\title{
Choice of Eco-friendly Trees in Urban Environment to Mitigate Airborne Particulate Pollution
}

\author{
Onkar J. Chakre \\ The Wealth of India Project, National Institute of Science Communication and Information \\ Resources, CSIR, 14 S. V. Marg, New Delhi 110067, India \\ Telephone: 011-26560141/43, Extension 432(O), 011-28745983(R) \\ E-mail: (ojc@niscair.res.in)
}

KEYWORDS RSPM. Urban Environment. Trees. Pollution. Lee-Side. Luff-Side. Shelter-Belts

ABSTRACT Trees in urban areas play an essential role to cleanse the airborne particulate pollution in human environment. The paper describes the choice of eco-friendly trees and their right placement in the urban environment to overcome the pollution problems.

\section{INTRODUCTION}

With the advent of economic growth, the urban environment of India has become predominated by concrete high-rise structures and a place of congestion, both from traffic, and commercial activities. The degeneration of our living environment in urban areas is largely due to new housing and townships, electrification, metro rails, widening of roads, rush of the automobiles etc. As a result, the balance of urban climate has been disrupted and most of the vegetation has been destroyed to make way for the so-called 'urban development.'

The vary air we breathe contains not only nitrogen, $78.8 \%$; oxygen, $20.15 \%$; carbon dioxide, $0.3 \%$ and certain traces of gases such as helium, hydrogen and methane but also the presence of dust particles, fumes, oxides of sulpher, carbon monoxide, hydrocarbon etc. The airborne particulate matter commonly known as dust, also referred to Respirable Suspended Particulate Matter (RSPM) is one of the major constituents of air pollution, which plays an important role in man-environment relationship (Gregory, 1973). Figure 1 reveals that the air contents fine particles of coal, smoke, radio nuclei, pesticides and other aero-biologically significant materials such as pollen grains, fungal spores, bacteria, algal filaments etc. The size of these major atmospheric particles ranges from $0.002 \mu \mathrm{m}-100 \mu \mathrm{m}$ (Chakre, 1979).

According to the WHO report, about 10 to $15 \%$ of the total population of India is suffering from common cold, bronchitis, asthma, hay fever etc. These diseases are no doubt airborne and spread the infection from several hundred kilometers under favourable atmospheric conditions. Dust and soot in the air contribute to between 20 and 200 deaths each day in America's biggest cities. Ill health from microscopic particulates with tiny specks smaller than the width of a human hair can lodge deep in the lungs and are associated with respiratory diseases, heart attacks and premature deaths. The new research indicates elderly people suffer the most harm. In the United States the Environmental Protection Agency (EPA) currently sets the maximum allowable concentration of microscopic particles at $150 \mu \mathrm{m} / \mathrm{m}^{3}$ of air.

The air is being continuously polluted in urban areas through heavy traffic, industry, domestic fuel combustion, stone quarries, coalmines and various agricultural activities from the adjoining areas. These particulates are no doubt dangerous to human health and environment causing various diseases to plants and animals, damage to properties including our cultural heritage, national monuments, archives etc. Dust concentration varies from place to place and hour to hour, diurnally depending upon traffic, type of industry etc. The highest dust concentration tends to be in summer, reaching maximum during mid-day and late-afternoon. In some large cities where wind and temperature fall more steadily, the concentration of dust also reduces accordingly.

\section{ROLE OF TREES}

In urban areas, plantation is ensured in parks, residential localities, street and road 
avenues and industrial sites as shelter-belts plantation. They act as efficient filters of airborne particles because of their large size, high surface to volume ratio of foliage, frequently hairy or rough leaf and bark surfaces. The interception and retention of atmospheric particles through the wind current either passing through the screens or subjected to curve over the plantation. The wind current further increases and can enter back into same trees is highly variable and primarily dependent on size, shape, degree of wetness and surface texture of the particles with microclimatic conditions. Trees are usually planted mainly in rows as thin and thick screens. In thin screen plantation, the trees are scattered and loosely planted; while in thick plantation, they are densely planted. Figure 2a indicates that each plantation has two sides. A front-side where the air current diverts or redirected before entering the plantation is known as Luff-side. Lee-side is a back-side of the plantation where the wind current fall either passing through the screens or subject to curve

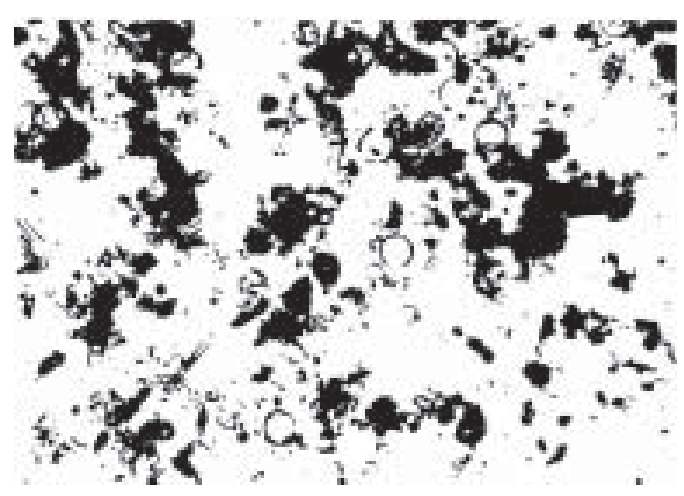

Fig. 1. Particulate pollutants suspended in air.

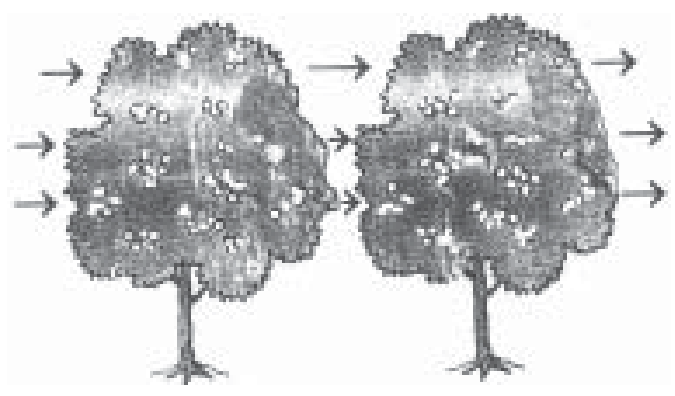

Fig. 2a. Loose plantation - good filtering effects over the plantation. The wind current further increases and can enter back into same plantation. Such type of reaction mostly occurs in thicker plantation (Bernatzky, 1978).

Figure $2(\mathrm{a} \& \mathrm{~b})$ shows that in thin-screen plantation, the in-coming air-current can enter easily and settle the impurities inside the plantation; because the wind current carrying capacity is largely reduced. The maximum dust concentration here occurs behind the plantation and from there it falls steadily, with the distance from the source of the dust. On the other hand, dust concentration falls rapidly inside the thicker plantation, reaching the maximum on the Luffside and the minimum on the Lee-side. But, from Lee-side the concentration of dust again increases due to increased wind velocity, the lighter particles are easily carried along over the obstacle (plantation) and whorled along with the air currents as described earlier.

In thicker plantation, a fall out of dust also occurs as a side-effect of turbulence but not like as in thin plantation. Therefore, dense plantation has a less filtering effect as compare to thin plantation. In both these plantations, the heavier particles settle down immediately on the leaf surface through impact due to gravitational force.

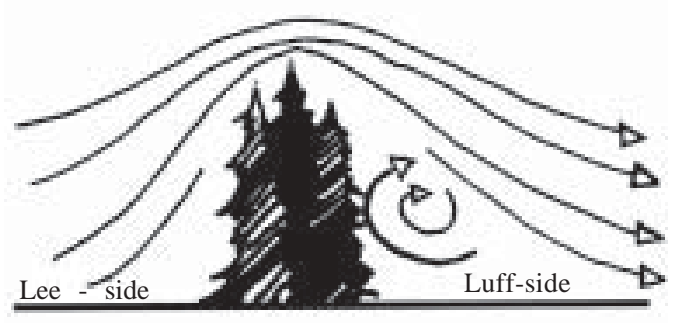

Fig. 2b. Thick plantation - small filtering effects.

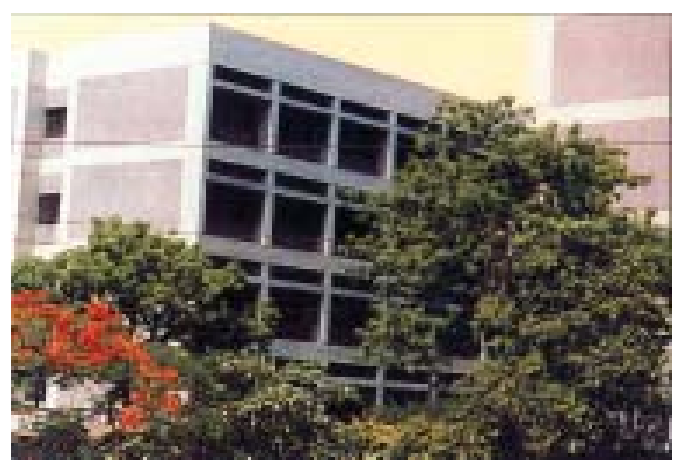

Fig. 3. Plantation near dwellings. 
Whereas, the lighter particles especially of microscopic nature, are found suspended in air for a longer time, as gravity does not affect them. Dust sedimentation also varies from tree to tree within the same plantation. In some species of trees the sedimentation is more in the apical region, whereas in others, it is at conical and basal regions. However, Bernatzky (1978) stated that it should not be ignored that the trees also suffer from dust and gaseous pollution and in recent times it has been reported that the dust injures them less than the toxic gases. He also further reported that the trees can also filter out the noxious gases accumulated into particulate matter.

Figure 3 reports the shelter-belts in various forms of plantations; thus act as dust filters especially when laid down at right angles to the main wind direction depending upon situation and purpose. These shelter-belts help to reduce the atmospheric particulate matter entering from flats, offices, schools and other objects to be protected. Besides, trees around industrial sites also help to purify industrial emissions.

During tree plantation in an urban environment little or no attention has been paid to evaluate the effect of trees on filtering the particulate matter. New housing developments offer an opportunity to control atmospheric particulate pollution through tree plantations. Trees such as Tamarind (Tamarindus indicus) having smaller compound leaves are generally more efficient particle collectors than larger leaves. Particle deposition is heaviest at the leaf tip and along leaf margin. In the preliminary survey of dust fall on common roadside trees in Mumbai, carried out by Shetye and Chaphekar (1980) reported that the shape of leaves of Mango (Mangifera indica), Ashoka (Polyalthea longifolia), Pongamia (Derris indica) and Umbrella (Thespepsia populnea) trees captured higher amounts of dust as compared to other neighboring plants. Dochinger (1973), a plant pathologist of USDA Forest Service, Ohio, reported that the filtering effects of evergreen trees are better than the deciduous trees. In Singapore; it has been noted that a single row of trees planted with or without shrubs can reduce particulate matter by $25 \%$ and each hectare $(2.471$ acres) of plantation can produce enough oxygen to keep about 45 persons alive (Anonymous, 1981).

\section{CHOICE OF ECO-FRIENDLY TREES}

The value of trees in urban environment is now generally recognized not only aesthetically but also functionally in helping to make cities and towns agreeable places to live and work in. The first choice should be, therefore, to select easily propagated and readily available, mediumgrowing, ecologically much suitable, pest and disease resistant tree species and also require less maintenance should be given top priority. Columnar and medium-sized trees are preferred. Ingold (1971) reported that the leaves with complex shapes and large circumference area reported to be collected particles more efficiently. Many trees like Neem (Azadirchta indica), Silk cotton (Bombax ceiba), Indian laburnum (Cassia fistula and C. siamea), Gulmohar (Delonix regia), Pipal (Ficus religiosa), Jacaranda (Jacaranda mimosifolia), Indian lilac (Lagerstroemia indica), Temple or Pagoda tree (Plumeria rubra and P. alba), Java plum (Syzygium cumini) and several other roadside and street trees have found more suitable in urban environment (Maheshwari, 1963; Oommanchan, 1977; Pokhriyal and Subba Rao, 1986; Chee, 1984). If such trees are to be planted, their local ecological relationship with human environment has to be studied properly. It should be borne in mind that these trees may cause allergic disorders such as hay fever; asthma and toxemia due to airborne pollen grains, which can also contribute to atmospheric pollution significantly. Chakre (1984) has suggested that the insect-pollinated trees with short flowering periods and also with less pollen productivity should be selected. It is also recommended that wind-pollinated tree species those, flowering during rainy season can also be planted, as rains will wash out extra pollens. A tree should be relatively free of insects and diseases and there should not be dropping of messy fruits ( Muntingia calabura, Cerbera odolam ), seed pods (Acacia auriculaeformis), twigs and leaves (Dyera costulata). Trees with a tendency to drop large and heavy fruits (Durio spp.) and emit bad smell (Sterculia foetida) must be considered a serious drawback.

\section{CONCLUSION}

The importance of trees in urban environment is now widely recognized that they too cleanse the particulate air pollution and help 
to make cities and towns more agreeable places to dwell upon. India's rich biodiversity of both indigenous and exotic trees, offers a wide range of choice to restore our sick and sultry towns. The present paper recommends various tree species for urban plantings, so that a wider usage of local as well as exotic tree species can be explored for controlling airborne particulate pollution in urban climate. However, a basic knowledge of their biological relationship with human environment is absolutely necessary in which arboculturists, environmental scientists, and town planners can work together. Much more research on urban trees is needed for effective control of atmospheric particulate pollution.

\section{REFERENCES}

Anonymous: A Guide to Tree Planting. Parks and Recreation Department, Ministry of National Development, Singapore (1981).

Bernatzky, A.: Tree Ecology and Preservation, Development in Agricultural and Management
Forest Ecology, 2 Elsevier Scientific Publishing Co. New York (1978)

Chakre, O. J.: Microbial Pollution of Air at Aurangabad Atmosphere: Unpublished Ph. D Thesis, Marathwada University, Aurangabad, India (1979).

Chakre, O. J.: Atmospheric pollens: The organic pollutants. Science Service, 3(8): 4 (1984).

Chee, T. Y. and Ridwan, S.: Fast-growing species of trees suitable for urban roadside and shade planting. Malaysian For, 47: 263-284 (1984).

Dochinger, L. S.: Miscellaneous Publication No.1230. USDA, Forest Service, Upper Darby, Pa, pp. 22 (1973).

Gregory, P. H.: The Microbiology of the Atmosphere. (1961). (2 ${ }^{\text {nd }}$ Ed.). Leonard Hill (Books) Ltd., Aylesbury , U. K. (1973).

Ingold, C. T.: Fungal Spores. Clarendon Press, Oxford (1971).

Maheshwari, J. K: The Flora of Delhi. Council of Scientific and Industrial Research, New Delhi (1963).

Oommanchan, M.: The Flora of Bhopal (Angiosperms). J. K. Jain Brothers, Bhopal (1977)

Pokhriyal, T.C. and Subba Rao, B. K., Role of forests in mitigating air pollution. Indian For. 112: 573-582 (1986).

Shetye, R. P., and Chaphekar, S. B.: Some estimations on dust fall in the city of Bombay, using plants. Vol. 4: pp. 61-70. In: Progress in Ecology. V. P. Agarwal and V.K. Sharma (Eds.). Today and Tomorrow's Printers and publishers, New Delhi (1980). 